\title{
AMOr e SeXo são (TAMBÉm...) Química
}

\author{
Madalena M. M. Pinto \\ Centro de Química Medicinal da Universidade do Porto, Departamento de Química, Laboratório de Química Orgânica e Farmacêutica, \\ Faculdade de Farmácia da Universidade do Porto \\ madalena@ff.up.pt
}

Amor e o Sexo são (também...) Química” porque muito do que se encontra na base das várias emoções associadas ao amor, à paixão e ao sexo, bem como à comunicação entre indivíduos da mesma espécie é...pura química! Neste artigo é dada ênfase aos principais grupos de moléculas intervenientes em eventos químicos endógenos, associados a mecanismos hormonais e neurotransmissão cerebral que, interactuando entre si, modulam muitos dos fenómenos que explicam comportamentos psico-socio-sexuais.

Assim, serão indicadas, com exemplos estruturais, famílias químicas nomeadamente esteróides, ácidos gordos, derivados aminados e péptidos, e a respectiva associação com acontecimentos e estados de espírito encontrados em diferentes fases da vida associadas ao amor e ao sexo.

\section{INTRODUÇÃO}

Quando se fala de um “triângulo amoroso” não se pressupõe, à partida, que se esteja a falar sob o ponto de vista químico, mas tal pode ser o caso...e como? Quando duas pessoas apaixonadas dizem frases como "amor à primeira vista” ou “há uma química entre nós” provavelmente estarão literalmente certos, pois há várias substâncias químicas a nível cerebral associadas a esse estado de espírito. Num quadro de enamoramento, paixão, ligação amorosa e desejo sexual é possível encontrar três fases principais que podem estar em sequência ou, em alguns casos, coexistir no mesmo indivíduo e às quais estão associadas moléculas de natureza química variada (Figura 1). Para que essas substâncias exerçam a sua bioactividade terão que, ao interagir com o alvo biológico, seguir o princípio universal do reconhecimento molecular. Para tal, as "pequenas moléculas” terão de ser reconhecidas pelas "biomacromoléculas alvo”, nomeadamente receptores, através da complementaridade de forma, estereoquímica e electrónica, formando um complexo que elicitará a resposta do organismo a esse estímulo químico.

\section{QUÍMICA CEREBRAL}

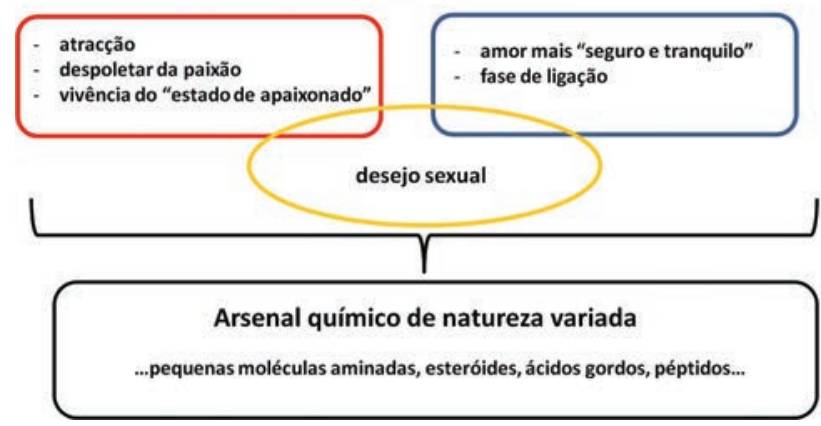

Figura 1 - Diversos tipos de moléculas associadas às diferentes fases do amor e do sexo

Assim, serão enumerados grupos de compostos que intervêm na definição dos géneros, na atracção entre os sexos e na explicação de fenómenos que muitas vezes influenciam os relacionamentos, como por exemplo, entre várias situações, a tensão pré-menstrual ou a necessidade do parceiro adormecer depois do acto sexual. O entendimento destes acontecimentos pode levar a uma melhoria do relacionamento entre os elementos de um casal ou a providenciar, se for o caso, potenciais soluções terapêuticas para algumas patologias.

\section{2. "Pequenas - Grandes" Moléculas...}

\subsection{ESTERÓIDES}

No arsenal químico dos esteróides, as hormonas sexuais são determinantes não só para a definição dos géneros, mas também pela intervenção nas várias fases referidas, desde a comunicação química à modulação na produção de outras substâncias intervenientes na fase de ligação, por exemplo.

As moléculas características das hormonas sexuais são de natureza esteróide, com a testosterona representando o protótipo molecular da masculinidade e do grupo dos androgénios, e com o estradiol e a progesterona como representantes do género feminino e dos grupos dos estrogénios e progestagénios, respectivamente (Figura 2).
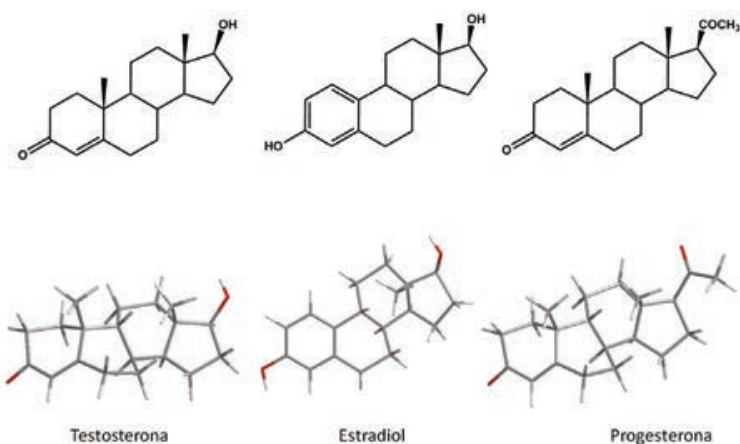

Figura 2 - Moléculas de esteróides características das hormonas sexuais masculinas (testosterona) e femininas (estradiol e progesterona) 
É interessante notar que estas hormonas, embora concorram de forma definitiva para a diferenciação dos géneros e das respectivas características secundárias, correspondem a compostos que apresentam aproximações interessantes:

- são encontrados concomitantemente em ambos os sexos, obviamente em concentrações diversas para cada um deles e também nas diferentes fases da vida [1];

- a nível biossintético verifica-se que o colesterol é a matéria-prima de todos eles e que todos se relacionam entre si através de modificações moleculares efectuadas por diversos sistemas enzimáticos [2] (Figura 3);

- a nível estrutural é possível encontrar várias semelhanças significativas, com porções moleculares das hormonas femininas a integrarem também a molécula da testosterona, como é o caso do anel D do estradiol e do anel A da progesterona que são idênticos aos existentes na testosterona (Figura 4). cipais aminoácidos foi determinada e avaliada por cristalografia de raios X e química computacional (Figura 5 A), assim como no caso do estradiol com o receptor estrogénico (Figura 5 B). Essas interacções dependem, para além da tridimensionalidade do esqueleto carbonado, da composição estrutural dos anéis A e D, levando assim à expressão da respectiva actividade biológica [3-7].

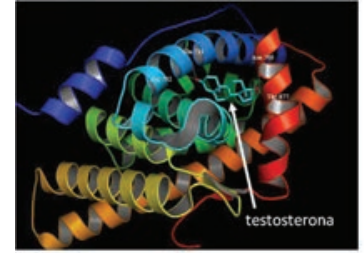

(A)

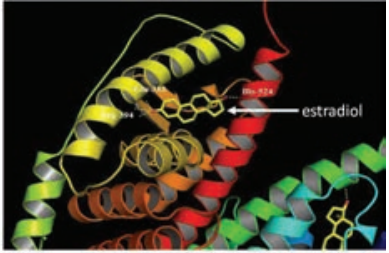

(B)
Figura 5 - Ligação da testosterona ao receptor androgénico (A) (http.//www.pdb.org;código: 2AM9) e ligação do estradiol ao receptor estrogénico (B) (http.//www.pdb.org;código: 1a52)

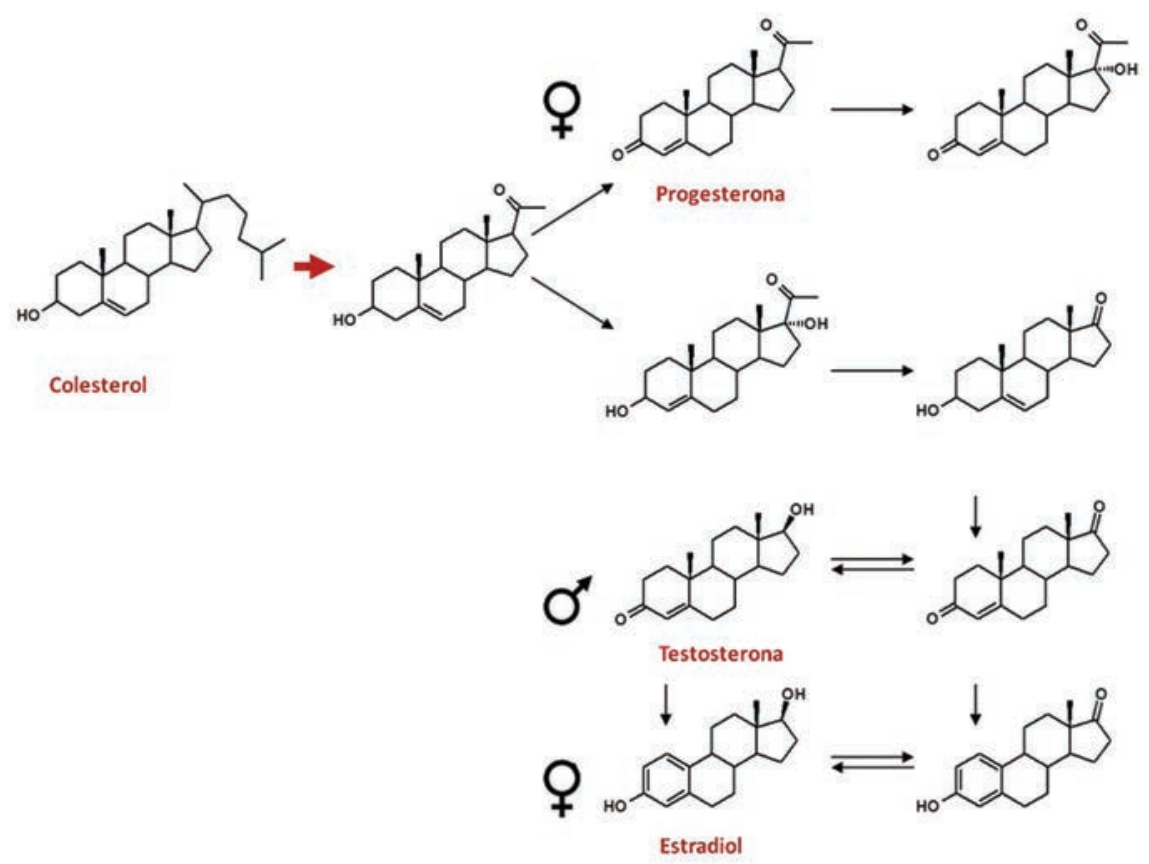

Figura 3 - Esquema biossintético simplificado para hormonas femininas e masculinas

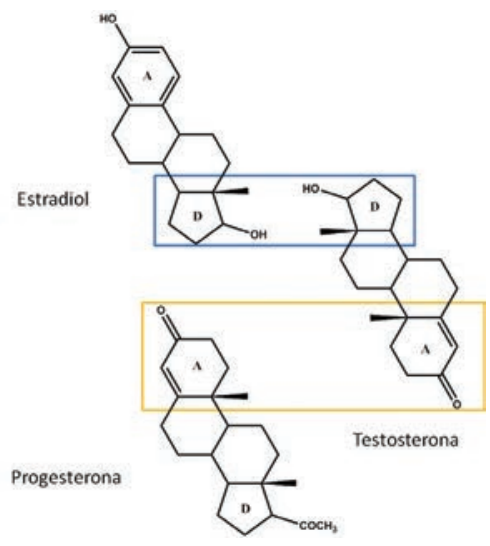

Figura 4 - Porções moleculares comuns a hormonas femininas e masculinas

O mecanismo de acção a nível molecular, no que concerne às hormonas sexuais, segue a regra universal do reconhecimento molecular entre a molécula activa e o bioalvo. A título de exemplo, a interacção da testosterona com os prin-
Mas a acção de moléculas esteróides não se limita à actividade hormonal, pois têm influência directa na modulação de outras substâncias intervenientes no amor e no sexo, como sejam a oxitocina e a vasopressina, que serão focadas adiante. A interligação das hormonas esteróides com a química cerebral, no que concerne a neurotransmissores, é também conhecida. Curiosamente a testosterona pode ser considerada como afrodisíaca para ambos os sexos [8], mas devemos ter em consideração que a quantidade de testosterona no homem é, dezenas a centenas de vezes, mais abundante que na mulher [9]. Assim, a testosterona activa o hipotálamo, levando a pensamentos eróticos e ao aumento de sensações nas zonas erógenas, provavelmente por induzir um aumento de libertação de dopamina; como veremos adiante a dopamina está associada a sentimentos de desejo e de sensação de recompensa.

A atracção entre géneros e a comunicação química em humanos ainda hoje são temas controversos e despertam inte- 
resse crescente, não só sob o ponto de vista científico, mas também pelo potencial comercial que podem envolver.

E aqui é quase imperioso mencionar as “famosas” ... feromonas! ${ }^{1}$

O termo feromonas foi cunhado por Karlson e Luscher em 1959 [10] para definir substâncias segregadas para o exterior por um indivíduo e recebidas por outro indivíduo da mesma espécie, no qual essas substâncias provocam uma reacção específica, um comportamento definido ou um processo de desenvolvimento.

Na área das moléculas associadas a substâncias feromonais é possível encontrar compostos odoríferos e não odoríferos, detectados pelos sistemas olfactivo e pelo órgão vomeronasal. Os esteróides associados a uma actividade dita feromonal pertencem a ambos os grupos e podem ser encontrados na pele, no suor, nos testículos e nos ovários [10-13].

Para os compostos encontrados em humanos e que não revelam odor, mas provocam alterações comportamentais em indivíduos usados como receptores nos ensaios efectuados, é presumido que actuam através da estimulação do órgão vomeronasal, independente do sistema olfactivo, mas com conexões ao hipotálamo; é de notar que este está ligado ao controlo de várias emoções, nomeadamente temperatura corporal, batimentos cardíacos e sexo [11-14].

Vários esteróides foram testados na procura de substâncias feromonais (Figura 6, números 1-7), sendo os mais activos os compostos (6) e (7) (Figura 6).

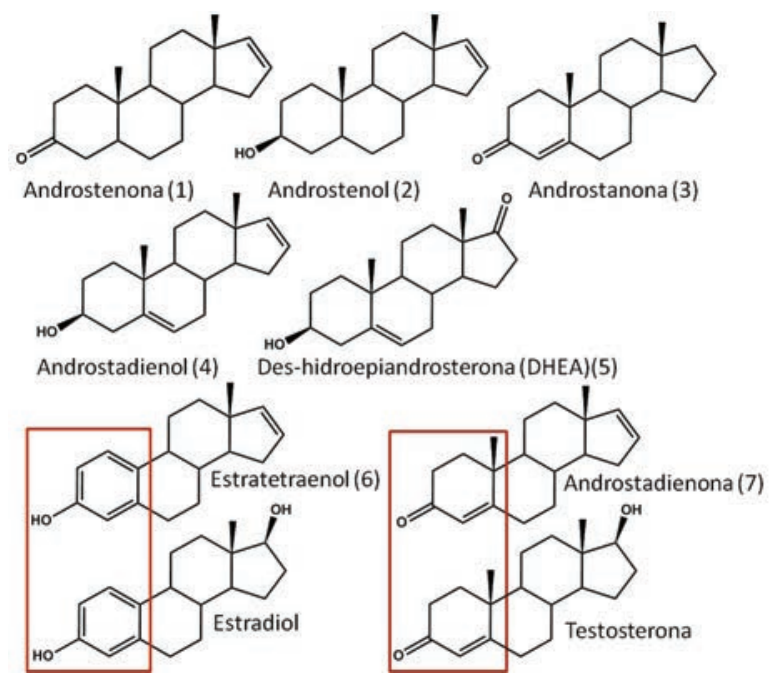

Figura 6 - Esteróides usados em testes de activação do orgão vomeronasal (1-7)

Dos resultados obtidos foi verificada que a reacção aos esteróides indicados (6) e (7) era género-dependente, ou seja, os homens mostraram-se mais sensíveis ao estratetraenol

\footnotetext{
1 Como as feromonas humanas não estão definitivamente comprovadas, o conceito associado neste artigo é o de feromonas putativas humanas.
}

(6) e as mulheres à androstadienona (7), o que poderá ser explicado pela semelhança estrutural com a hormona feminina estradiol e a hormona masculina testosterona, respectivamente (assinalada com um rectângulo na Figura 6) [15-20].

Muitos estudos foram desenvolvidos e algumas metodologias utilizadas contestadas, mas têm surgido na literatura resultados bastante interessantes envolvendo a actividade de esteróides [21-23].

Se se considerar esta área numa perspectiva da Química Medicinal, sem dúvida que poderemos encontrar um estímulo para quem pretender desenvolver fármacos que possam contribuir, tanto para a resolução de problemas de fertilização, como para novos desenvolvimentos na área da anticoncepção.

Outras substâncias pertencentes à família dos esteróides, designados de neuroesteróides, estão também envolvidas neste “jogo químico” no qual os “jogadores” são moléculas de natureza química tão variada.

Os neuroesteróides, dos quais são exemplos a pregnenolona e a des-hidroepiandrosterona (Figura 7), são produzidos tanto no sistema nervoso central como periférico, actuando de forma independente relativamente às hormonas sexuais $[24,25]$.
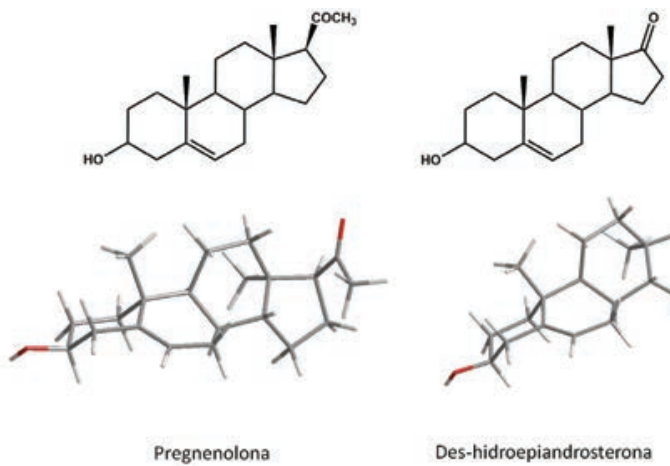

Figura 7 - Exemplos de neuroesteróides naturais

A pregnenolona e a des-hidroepiandrosterona, assim como os respectivos derivados sulfatados, são encontrados no cérebro de mamíferos, actuando em receptores não só do hipocampo, mas também da amígdala, podendo assim estar associados a respostas emocionais. O mecanismo de acção dos neuroesteróides não está ainda completamente entendido, mas testes com derivados sintéticos neuroactivos ajudam a alicerçar apreciações de que esta família de compostos tem influência na modulação noradrenérgica e serotoninérgica [25, 26], assim como impacto na libido [27]. Para além disso, parecem condicionar vários efeitos fisiológicos associados a diversas patologias mentais e distúrbios sexuais [28]. Assim, a este grupo de substâncias pode ser conferido um grande potencial terapêutico, pois poderão vir a ser medicamentos do futuro para várias áreas, nomeadamente tratamento da depressão e disfunção sexual masculina e feminina. 


\section{2 ÁCIDOS GORDOS E DERIVADOS}

É do conhecimento geral que certos odores têm a capacidade de influenciar as emoções, o humor e até os sistemas endócrino e imunitário. Esses efeitos podem estar associados a uma única substância ou a um "bouquet" de vários compostos e a capacidade de deteç̧ão de odores é género-dependente. Por exemplo, as mulheres manifestam uma maior capacidade para detectar odores do tipo almiscarado do que os homens; para além disso, a capacidade olfactiva varia ao longo do período menstrual, estando relacionada com o nível de estrogénios na circulação.

Assim, é fácil de entender porque é que a sensibilidade a certos odores está alterada em mulheres que tomam a pílula anticonceptiva, que se encontram em pós-menopausa e nas grávidas. Mas não estamos a falar de perfumes caros... estamos a falar do odor corporal! Na verdade os odores corporais feminino e masculino são diferentes, sendo o primeiro adocicado e o segundo almiscarado. E mais uma vez a química explica! O odor corporal masculino tem na sua composição esteróides, cetonas macrocíclicas e lactonas, que no conjunto conferem esse aroma almiscarado [14, 29, 30].

Sem dúvida que o odor corporal resultante do suor, que começa a ser produzido pelas glândulas sebáceas apócrinas durante a puberdade, tem composição diversa em homens e mulheres. Isso resulta não só da diversidade estrutural entre essas glândulas para os dois géneros, sobretudo a nível axilar, mas também do dimorfismo bacteriano que degrada as secreções glandulares inodoras, constituídas predominantemente por ésteres lipídicos, produzindo ácidos gordos responsáveis pelo odor caprino do suor (Figura 8) [31].

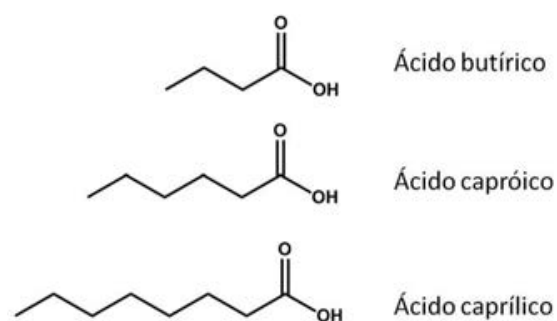

Figura 8 - Ácidos gordos associados ao odor caprino do suor

Mas não é só no suor que se pode encontrar esse tipo de ácidos gordos de baixo peso molecular. Também estão representados nas secreções vaginais, sendo designados de copulinas (Figura 9).<smiles>CC(=O)O</smiles>

Ácido acético<smiles>CCCC(C)=O</smiles>
Ácido propanóico

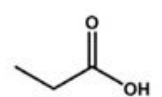<smiles>CC(C)CC(=O)O</smiles>

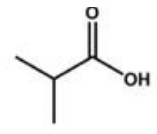

Ácido metilpropanóico<smiles>CCCC(C)C(=O)O</smiles>

Ácido butanóico Ácido 3-metilbutanóico Ácido 2-metilpentanóico

Figura 9 - Ácidos constituintes de secreções vaginais humanas
A composição qualitativa e quantitativa dessas substâncias varia durante o período menstrual, com uma concentração crescente até ao período da ovulação, com um odor menos forte e menos desagradável [32-37].

Segundo reza a história, Napoleão, que estava para regressar de uma batalha, numa carta enviada para a sua amada Josefina, pedia-lhe para ela não se banhar, de modo a deixar bem concentrado o seu odor natural...será que Napoleão já "sabia” o que eram copulinas?!

Vários estudos foram desenvolvidos com humanos e com macacos rhesus, tendo em alguns deles sido encontrados resultados de alteração na relação interpessoal em humanos. As mulheres às quais tinha sido feita aplicação de copulinas de fêmeas rhesus foram consideradas por alguns dos homens participantes no estudo como as mais interessantes [38].

Assim, é inegável que estas pequenas moléculas serão responsáveis por alterações comportamentais socio-sexuais; resta provar se podem ser consideradas feromonas...

\subsection{DeRIVAdos aminados - NeUROTRANSMISSORES}

Mas se os esteróides estão associados à definição dos sexos, à atracção e comunicação química entre indivíduos, há outras substâncias que manifestam um papel determinante no que se designa "amor à primeira vista" ou até que explicam o "estar a morrer de amor" por alguém! São as aminas biogénicas cerebrais que funcionam como neurotransmissores. Desse grupo podem ser destacados alguns compostos pelo seu papel interveniente na química do amor e do sexo (Figura 10).<smiles>CNCC(O)c1ccc(O)c(O)c1</smiles><smiles>NCCc1ccc(O)c(O)c1</smiles><smiles>NCC(O)c1ccc(O)c(O)c1</smiles><smiles>NCCc1c[nH]c2ccc(O)cc12</smiles>

Figura 10 - Exemplos de algumas aminas cerebrais

A $\beta$-feniletilamina está ligada à fase da paixão, em que os enamorados se sentem num estado de euforia. Estruturalmente a $\beta$-feniletilamina é muito semelhante à anfetamina, podendo intensificar a neurotransmissão catecolaminérgica, acelerando o fluxo de informação entre neurónios, aumentando o nível de dopamina [8,39].

A $\beta$-feniletilamina é rapidamente metabolizada pela enzima monoaminoxidase, permanecendo pouco tempo na 
fenda sináptica, mas pelas características da sua acção é muitas vezes associada ao "amor à primeira vista” e designada de “cupido químico”.

A dopamina é uma das aminas biogénicas cerebrais que desempenha um papel fundamental na fase da paixão e enamoramento, na fase do amor romântico. O aumento da dopamina está associado a uma focagem de atenção no ser amado, com um comportamento predominantemente dirigido para o alvo da paixão [40, 41], considerando apenas as qualidades, vendo o ser amado como especial [42]. Outros sintomas desta fase são a exaltação mental, falta de sono e de apetite [43]. Os níveis de dopamina explicam o comportamento que caracteriza o "mecanismo de recompensa quí- jogo, correspondendo a outra fase do desenvolvimento emocional na área do amor: os péptidos.

\subsection{PÉPTIDOS}

No grupo dos derivados peptídicos as endorfinas e encefalinas, assim como a oxitocina e a vasopressina, têm um lugar de destaque.

As endorfinas, tal como o nome indica (derivado de endo interno e morfina), estão associadas a analgesia endógena [49] e as primeiras encontradas foram isoladas do hipotálamo, existindo quatro tipos: $\alpha, \beta, \gamma$ e $\delta$. Na Figura 11 encontra-se o exemplo da estrutura da $\alpha$-endorfina.

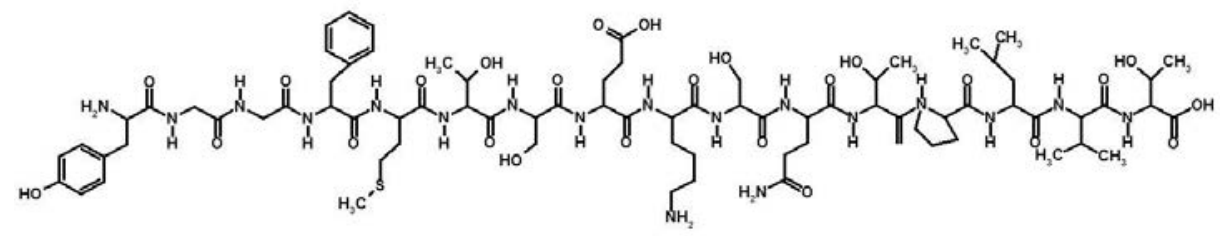

\section{$\alpha$-Endorfina}

Figura 11 - Exemplo da estrutura de uma endorfina

mica”, associado a sensações de excitação, maior energia e euforia, levando em certos casos a uma dependência dessa sensação de felicidade, se o sentimento é correspondido, ou de autodestruição, se é contrariado, levando ao aumento da produção de dopamina que leva a um maior empenho na conquista do objecto do desejo [44, 45].

A noradrenalina é a precursora da adrenalina; assim, um aumento desta amina biogénica leva, por exemplo, à sensação de euforia e taquicardia. A actividade manifestada pela noradrenalina depende da região cerebral que é activada. Nas pessoas apaixonadas o aumento de noradrenalina leva a estados de energia aumentada, episódios de insónia, perda de apetite e lembranças de pormenores de momentos que foram passados com o ser amado [46].

A serotonina, ou 5-hidroxitriptamina, é associada frequentemente à fase do amor romântico e à tendência para o “sonhar acordado". A alteração dos níveis de serotonina explica também os pensamentos irresistíveis e até obsessivos sobre o(a) parceiro(a) [41], sendo que esta situação tem semelhanças com o que acontece em quadros patológicos obsessivo-compulsivos. Em estudos a nível cerebral foi verificado que a concentração de serotonina era semelhante em apaixonados e pacientes que manifestavam essa doença $[47,48]$. Tendo em conta o que se sabe destes neurotransmissores e a sua implicação na fase da paixão não será por acaso que um filme que fez sucesso se intitulava “O amor é o melhor remédio” (no original: “Love \& other drugs”).

Mas tendo em conta os efeitos referidos para essas substâncias, com predominância para efeitos excitatórios, focagem cerebral, etc., é previsível que esse estado não possa “durar para sempre”...assim, outras moléculas entram em
As encefalinas são também péptidos de menor dimensão (Figura 12) e, conjuntamente com as encefalinas e as dinorfinas, são apelidadas de “opióides endógenos”.

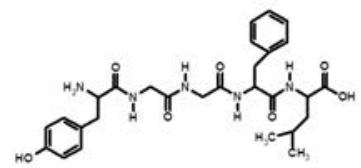

Leu - encefalina

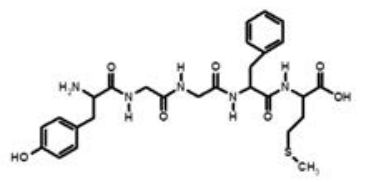

Met - encefalina
Figura 12 - Exemplo de estruturas de duas encefalinas (LeucinaEncefalina e Metionina-Encefalina)

É interessante notar que a produção destas substâncias, a nível cerebral e na hipófise, está associada à produção de estrogénios, com estes a induzirem a expressão de genes para receptores de encefalinas; este facto poderá estar relacionado com a capacidade feminina de tolerar a dor a estímulos fortes durante o acto sexual [50]. Na verdade as endorfinas desempenham um papel importante no comportamento sexual, pois o acto de tocar o parceiro, de trocar olhares ternos, por exemplo, convida a uma troca amorosa. Como já foi referido, estas substâncias encontram-se associadas à fase do amor relacionada com uma maior tranquilidade, sentimentos de estabilidade e bem-estar aumentando o envolvimento entre os parceiros.

Quanto à oxitocina e à vasopressina, as respectivas estruturas foram determinadas por Vincent du Vigneaud em 1953, o que lhe valeu o Prémio Nobel da Química (1995). Estes dois neuropétidos, que funcionam como neuro-hormonas, têm estruturas muito semelhantes (Figura 13), ambas contendo nove aminoácidos, em que dois resíduos de cisteína se encontram ligados por uma ponte dissulfureto; a oxito- 
cina e a vasopressina diferem na respectiva sequência por dois aminoácidos (Figura 13).

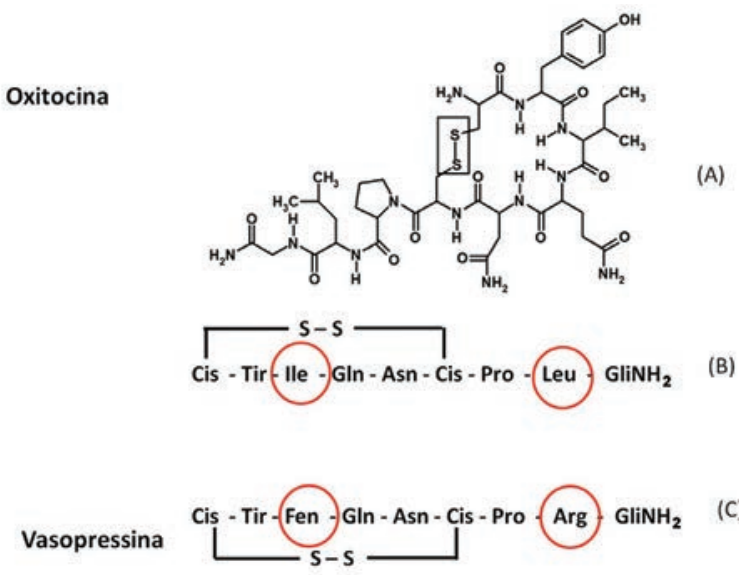

Figura 13 - Estrutura da oxitocina com indicação dos aminoácidos constituintes e da ligação dissulfureto (A), representação simplificada (B), comparativamente com a vasopressina (C) (aminoácidos diferentes nas duas estruturas - destacados em círculos).

A inter-relação da oxitocina com as hormonas sexuais não deverá ser ignorada. A produção de estrogénios e testosterona aparece aumentada por influência da oxitocina, mas a relação da oxitocina com as hormonas femininas é mais significativa na medida em que acontece de uma forma concertada; ou seja, a produção de oxitocina também é modulada por estrogénios e progesterona. Os níveis de estrogénios aumentados podem explicar a maior sensibilidade ao toque por parte da mulher em certas fases do período menstrual e, no caso da progesterona, a diminuição rápida no momento do parto estará associada ao aumento da oxitocina que intervém nas contracções uterinas e na produção do leite materno.

A relação com a dopamina também não pode ser excluída, pois experiências com animais puseram em evidência que a intervenção concertada da oxitocina e vasopressina com sistemas dopaminérgicos poderá estar associada a sensações de recompensa [51]. Talvez daí a sensação "gostosa" que é sentida entre os parceiros depois de "fazerem as pazes” após uma zanga ...

Embora os efeitos destas substâncias, no que se refere à sua intervenção no relacionamento entre os parceiros, ainda tenha alguns aspectos não completamente clarificados [50], alguns trabalhos de pesquisa desenvolvidos demonstraram que a oxitocina e a vasopressina estão implicadas na resposta sexual humana [52].

Foi verificado que os níveis de oxitocina subiam durante o orgasmo em ambos os sexos e que a vasopressina aumentava no homem durante a excitação sexual, voltando ao nível normal depois da ejaculação; quanto à oxitocina demorava cerca de 30 minutos a regressar ao nível normal. Os níveis de oxitocina e vasopressina parecem afectar a amígdala, modulando a intensidade da excitação durante o orgasmo e na fase pós-coito [52].

A secreção de oxitocina e de vasopressina aumenta pela estimulação dos genitais e dos mamilos durante o acto se- xual e o orgasmo. Assim, também a Química explica a importância da fase dos “preliminares”...a oxitocina aumentando fortemente na mulher e a vasopressina no homem, contribuem para a contracção uterina e para a manutenção da erecção, levando a uma sensação de união, ligação entre os parceiros e sensação de bem-estar [53].

Sem dúvida que as conclusões mais recentes apontam para a confirmação de que a oxitocina e a vasopressina contribuem de uma forma importante para a atracção, para a sensação de ligação e até do “curar as feridas” após uma briga entre os parceiros. Por isso, muitos abraços, muitos beijos, muitos olhares românticos e teremos aumentada a produção de oxitocina e de vasopressina [54]!

\section{CONCLUSÃo}

Como a Química não é “determinista” dever-se-á ter em conta todas as áreas que se encontram na base dos fenómenos referidos e que, de uma forma interdisciplinar, contribuem para o seu entendimento, nomeadamente, fisiologia, antropologia, bioquímica, psicologia...

A lição a tirar é que não é possível produzir o amor numa reacção de laboratório (nem nos deveremos deixar tentar por essa ideia...), mas que amor e sexo sem química não existem!

Como conclusão final poder-se-á dizer que todas as moléculas intervenientes no amor e no sexo funcionam "em rede” (Figura 14), ou seja, devem “jogar” entre si para que haja um comportamento harmonioso, a nível bioquímico, fisiológico, psicológico emocional...enfim, para que possamos ser felizes nos nossos relacionamentos, nas diferentes fases da vida.

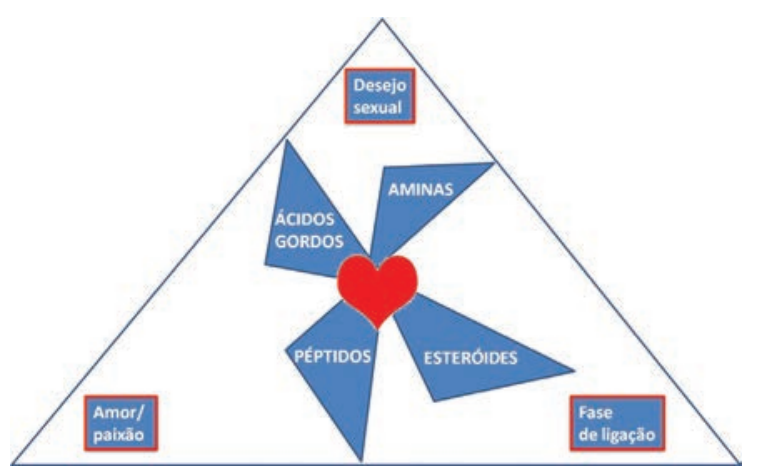

Figura 14 - Interligação entre as substâncias envolvidas nas diferentes fases do amor e do sexo

\section{Agradecimentos}

À Doutora Marta Correia da Silva pela colaboração na elaboração de algumas figuras.

\section{REFERÊNCIAS}

[1] D. Cadbury, The feminilization of nature - our future risk, Penguin Books, London, 1997 
[2] T. Nograday, Medicinal Chemistry - A Biochemical Approach, Oxford University Press, Inc., New York, 1988

[3] E. Ottow, H. Weinnmann, Nuclear Receptors as Drug Targets, WILEY-VCH Verlag GmbH \& Co. KGaA, Weinheim, 2008

[4] W. L. Duax, J. F. Griffin, D. C Rohrer, "Steroid conformation, receptor binding, and hormone action", in A.S. Horn, C.J. de Ranter (ed.), X-ray crystallography and drug action, Oxford University Press: New York (1984) 405.

[5] R.E. Babine, "Molecular Recognition of Nuclear Hormone Receptor-Ligand Complexes” in R.E. Babine, S.S. AbdelMeguid (ed.), Protein Crystallography in Drug Discovery, WILEY-VCH Verlag GMBH \& Co. KGaA: Weinheim (2004) 1.

[6] H. Kubinyi, "Hydrogen Bonding: The Last Mystery in Drug Design?” in B. Testa, H. van de Waterbeemd, G. Folkers, R. Guy (ed.) Pharmacokinetic Optimization in Drug Research-Biological, Physicochemical and Computational Strategies, Verlag Helvetica Chimica Acta, Zurich, WileyVCH: Weinheim (2001) 513.

[7] K.P. Jesus-Tran, P.L. Côté, L. Cantin, J. Blanchet, F. Labrie, R. Breton, Protein Science 15 (2006) 987-999.

[8] H. Fisher, Why we love?, Henry Holt and Company, LLC., New York, 2004.

[9] R.S. Swerdlof, C. Wang, A.P.S. Hikim "Hypothalamic- pituitary-gonadal axis in men” in D.W. Pfaaf, A.P. Arnold, A.M. Etger, S.E. Fahrbach, R.T. Rubin (ed.) Hormones, Brain and Behavior, Elsevier Science: USA (2002) Vol. 5, 1.

[10] P. Karlson, M. Luscher, Nature 183 (1959) 55-56.

[11] K.P. Bhatnagar, T.D. Smith, J. Anat. 199 (2001) 289-302.

[12] R. Tirindelli, C. Mucignat-Caretta, N.J. Ryba, Trends Neurosci. 21 (1998) 482-486.

[13] J. N Labows Jr., “Odor detection, generation and etiology in the axilla”, in C. Felgen, K. Laden (ed.) Antiperspirants and deodorants, Marcel Dekker: New York. (1988) 321343.

[14] M. Halpern, A. Martinez-Marcos, Prog. Neurobiol. 70 (2003) 245-318.

[15] L. Monti-Bloch, B.I. Grosser, J. Steroid Biochem. Mol. Biol. 39 (1991) 573-582.

[16] S. Jacob, L.H. Kinnunen, J. Metz, M. Cooper, M.K. McClintock, Neuroreport. 12 (2001) 2391-2394.

[17] B.I. Grosser, L. Monti-Bloch, C. Jennings-White, D.L. Berliner, Psychoneuroendocrinology. 25 (2000) 289-299.

[18] S. Jacob, M.K. McClintock, Horm. Behav. 37 (2000) 57-78.

[19] S. Jacob, S. Garcia, D. Hayreh, M.K. McClintock, Horm. Behav. 42 (2002) 274-283.

[20] S. Jacob, D.J. Hayreh, M. K. McClintock, Physiol. Behav. 74 (200) 15-27.

[21] S.L. Black, C. Biron, Behav. Neural. Biol. 34 (1982) 326330.

[22] I. Savic, H. Berglund, B. Gulyas, P. Roland, Neuron. 31 (2001) 661-668.

[23] N.M. Morris, J. Udry, J. Biosocial. Sci. 10 (1978) 147-157.

[24] S. Kawato, M. Yamada, T. Kimoto, Adv. in Biophys. 37 (2003) 1-48.

[25] S.H. Mellon, L.D. Griffin, TRENDS in Endocrinology \& Metabolism 13 (2002) 35-43.

[26] F. Broekhoven, R.J. Verkes, Psychopharmacology 165 (2003) 97-110.
[27] S.R. King, D.J. Lamb, Sexuality, Reproduction \& Menopause 4 (2006), 20-23.

[28] R.D. Strous, R. Maayan, A. Weizman, Eur. Neuropsychopharmacol. 16 (2006) 155-230.

[29] B.W. Brooksbank, D.A. Wilso, D.A. MacSweeney, J. Endocrinol. 52 (1972) 239-251.

[30] D.B. Gower, B. A. Ruparelia, J. Endocrinol. 137 (1993) 167-187.

[31] D.B Gower, A. Nixon, A.I Mallet, “The significance of odorous steroids in axillary odour”, in S. Van Toller, G.H. Dodd, (ed) Perfumery: the psychology and biology of fragrance, Chapman \& Hall: London (1988) 47.

[32] K. Grammer, B. Fink and N. Neave, Eur. J. Obstet. Gynecol. Reprod. Biol. 118 (2005) 135-142.

[33] R.P. Michael, R.W. Bonsall, M. Kutner, Psychoneuroendocrinology 1 (1975) 153-163.

[34] R.F. Curtis, J.A. Ballantine, E.B. Keveren, R.W. Bonsall, R.P. Michael, Nature 232 (1971) 396-398.

[35] G. Preti, G R. Huggins, J. Chem. Ecol. 1 (1975) 361-376.

[36] R.P. Michael, R.W. Bonsall, P. Warner, Science 186 (1974) 1217-1219.

[37] R.L. Doty, M. Ford, G. Preti, G.R. Huggins, Science 190 (1975) 1316-1318.

[38] J.J. Cowley, A.L. Johnson, B. W. Brooksbank, Psychoneuroendocrinology 2 (1977) 159-172.

[39] H. Fisher, A. Aron, D. Mashek, H. Li, L.L. Brown, Archives of Sexual Behavior 31 (2002) 413-419.

[40] W. Schultz, Nature Reviews Neuroscienc. 1 (2000) 199207.

[41] M. Luciana, P.F. Collins, R.A. Depue, Cerebral Córtex 8 (1998) 218-226.

[42] S.L. Murray, J.G. Holmes, Personality and Social Psychology Bulletin 23 (1997) 586-604.

[43] N.D. Volkow, G.-J Wang, M.W. Fischman, R.W. Foltin, J.S. Fowler, N.N. Abumrad, S. Vitkun, J. Logan, S.J. Gatley, N. Pappas, R. Hitzemann, C.E. Shea, Nature 386 (1997) 827-830.

[44] A. Abbot, Nature 419 (2002) 872-874.

[45] W. Schultz, P. Dayan, P.R. Montague, Science 275 (1997) 1593-1598.

[46] M.G. Griffin, G.T. Taylor, Behavioral Neuroscience 109 (1995) 466-473.

[47] D. Marazziti, H.S. Akiskal, A. Rossi, G.B. Cassano, Psychological Medicine 29 (1999) 741-745.

[48] E. Hollander, M. Fay, B. Cohen, R. Campeas, J.M. Gorman, M.R. Liebowitz, Am. J. Psychiatry 145 (1988) 10151017.

[49] M.E.M. Martinez, N. Pedrón, Ginecologia \& Obstetricia de México 67 (1999) 183-187.

[50] O.W. Pfaff, DRIVE, Neurobiological and Molecular Mechanisms of Sexual Motivation. A Bradford Book, The MIT Press, Massachusetts, 1999.

[51] T.R. Insel, Physiol. Behav. 79 (2003) 351-357.

[52] J. Debiec, FEBS Letters 581 (2007) 2580-2586.

[53] G.C Gonzaga, R.A. Turner, D. Keltner, B. Campos, M. Altemus, Emotion 6 (2006) 163-179.

[54] J.-P. Goui, C.S. Carter, H. Pournajafi-Nazarloo, R. Glaser, W.B. Malarkey, T.J. Loving, J. Stowell, J.K. Kiecolt-Glaser, Psychoneuroendocrinology 35 (2010) 1082-1090. 


\section{Leitura Adicional}

- M.M. M. Pinto, Química do Amor e do Sexo, Lidel - edições técnicas, Lda, Lisboa, 2010
- M.M.M. Pinto, Chemistry of Love and Sex, Verlag Helvetica Chimica Acta, Zurich (Switzerland) and WILEY-VCH, Weinheim (Federal Republic of Germany), 2012

\section{Actualidades Científicas}

\section{A ENERGIA POR DETRÁS DA SOPA PRIMITIVA}

Embora seja geralmente aceite que alguns compostos químicos importantes para a vida vieram de meteoritos que bombardearam a Terra primitiva, os investigadores não têm sido capazes de explicar como é que rochas inanimadas se transformaram nos blocos do edifício da vida.

Bryant et al. (2013) mostraram como um composto químico, análogo ao que é encontrado em todas as células vivas, e vital para produção da energia em qualquer ser vivo, poderia ter sido criado quando os meteoritos contendo minérios com fósforo caíram em ambientes quentes como lagos situados em zonas de vulcões, que seriam provavelmente comuns na Terra primitiva.

Toda a vida na Terra é alimentada por um processo quimiosmótico, em que o trifosfato de adenosina (ATP) é sintetizado durante a respiração e gasto para libertar a energia necessária para o metabolismo. Uma vez que as enzimas necessárias para a criação e quebra de ATP não deveriam existir na Terra durante o período em que a vida apareceu originalmente, isso levou os cientistas a procurar um composto químico mais simples mas com propriedades semelhantes ao ATP, que contudo, não necessitasse de enzimas para efectuar a transferência de energia.

O fósforo é o elemento chave da molécula de ATP e de outras biomoléculas fundamentais da vida, como o ácido desoxirribonucleico (DNA). O fósforo normalmente encontra-se na Terra sob a forma de fósforo(V), que é, em grande medida, insolúvel em água e apresenta uma baixa reactividade química. A Terra primitiva foi regularmente bombardeada por meteoritos e poeira interestelar rica em minérios exóticos, incluindo a forma mais reactiva de fósforo, o minério de ferro-níquel-fósforo schreibersite. Bryant et al. (2013) simularam o impacto de um meteorito numa zona quente vulcanicamente activa e fluida, nos primórdios da Terra. Para isso, colocaram amostras do meteorito Sikhote-Alin, um meteorito de ferro que caiu na Sibéria em 1947, no fluido ácido retirado da zona geotérmica de Hveradalur, na Islândia. As amostras foram deixadas a reagir com o fluido ácido, em tubos de ensaio incubados pela água termal quente circundante, durante quatro dias, e deixadas por mais 30 dias à temperatura ambiente. Ao analisar a solução resultante foi encontrado pirofosfito, $\left(\mathrm{P}_{2} \mathrm{O}_{5}\right)^{4-}$, semelhante ao pirofosfato $\left(\mathrm{P}_{2} \mathrm{O}_{7}\right)^{4-}$ que constitui a parte do ATP responsável pela transferência de energia.

Os investigadores acreditam que este composto pode ter actuado como uma forma primitiva de ATP, no que tem sido designado por "vida química”. Este teria sido, afinal, o passo intermédio entre a rocha inorgânica e a primeira célula biológica viva.

(adaptado do artigo de 08/04/2013: Origin of Life: Power Behind Primordial Soup Discovered, http://www.sciencedaily.com/releases/2013/04/130404122234.htm e D.E. Bryant, et. al. Geochimica et Cosmochimica Acta, 109 (2013) 90-112)

António Mendonça (mendonca@ubi.pt)

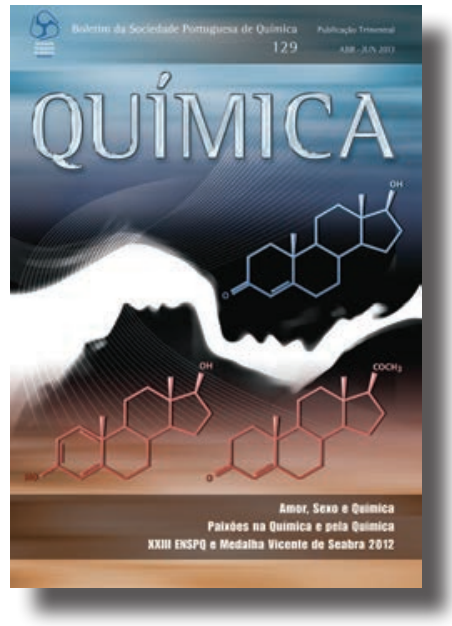

\section{Artigos Livros}

Notícias Entrevistas

\section{Duímica e Ensino} Agenda e Destaques

\section{Actualidades Científicas}

